\title{
Mulherio: estudo de caso de publicação da imprensa feminista brasileira nos anos 1980
}

Mulherio: a case study of the Brazilian feminist press in the 1980s

\section{KLAFKE, Raquel}

Universidade de São Paulo - USP I raquel.klafke@usp.br

BRAGA, Marcos da Costa

Universidade de São Paulo - USP I bragamcb@usp.br

\begin{abstract}
Resumo
O presente artigo consiste em uma análise da publicação Mulherio, jornal feminista veiculado em São Paulo e vendido a outros estados do Brasil nos anos 1980. As edições estudadas serão os números \#0 a \#15, período em que o projeto recebera subsídios da Fundação Ford. O objetivo da análise é reconhecer elementos visuais característicos da publicação estético-formais e técnico-formais -, tornando-se um registro histórico da imprensa feminista brasileira sob a perspectiva do design gráfico.
\end{abstract}

Palavras-chave: Mulherio. Design gráfico. Feminismo. Imprensa brasileira.

\section{Abstract}

This paper is an analysis of Mulherio, a feminist newspaper published in São Paulo and sold throughout Brazil in the 1980s. The examined sample ranges from numbers \#0 to \#15, during which the project received funds from the Ford Foundation. The purpose of this analysis is to identify the main visual elements of the publication - aesthetically and technically speaking - so to build a historical record of the Brazilian feminist press, from the graphic design perspective.

Keywords: Mulherio. Graphic design. Feminism. Brazilian press. 


\section{INTRODUĈ̣̃O}

\subsection{Objetivos}

Durante um período de conturbações econômicas, sociais e políticas, o design gráfico dos anos 1980 apresentou muitas peculiaridades em solo brasileiro - especialmente nos circuitos alternativos de cultura, que apontavam tendências contrastantes com a até então "mídia hegemônica" do mercado impresso. Desde fanzines da cena punk tupiniquim até produções de intelectuais relacionados à pesquisa acadêmica, as diferentes linguagens pareceram convergir para um fim comum: a comunicação - e, consequentemente, o design - como resistência política, apresentando não só conteúdos que convidassem à reflexão; mas também linguagens provocadoras (e até mesmo culturalmente subversivas) para criar identificação com seus leitores. Em meio a um amplo espectro de possibilidades de pautas, neste trabalho será analisada a linguagem visual do jornal Mulherio, publicação dedicada à veiculação de diversas ideias relacionadas à condição da mulher brasileira (seja cultural, política ou econômica) e às reinvindicações feministas que começaram a ganhar visibilidade no final da segunda metade do século XX no Brasil. O estudo comparativo entre edições tem como objetivo apresentar um panorama visual dos recursos estéticos e formais (VILLAS-BOAS, 2009) utilizados em Mulherio, que podem ser observados em outras publicações da mídia alternativa dos anos 1980.

\subsection{Material e Métodos}

Esse trabalho foi constituído a partir de uma perspectiva da microhistórica (OLIVEIRA, 2005), com intensa exploração de fontes primárias, aplicada ao estudo do feminismo no Brasil e suas relações com o design visual. Recorte definido, foram estabelecidos dois pilares metodológicos: levantamento bibliográfico - contextualizando os anos 1980 e a imprensa feminista, bem como a organização do material para análise gráfica - e entrevistas qualitativas, baseadas em métodos da História Oral', com duas figuras importantes na concepção do Mulherio - Adélia Borges², primeira editora do jornal, e Marlene Rodrigues, primeira editora visual ${ }^{3}$.

1 As depoentes autorizaram o uso de trechos das entrevistas ao concordar com os termos esclarecidos em suas respectivas cartas de Cessão de Direitos sobre Depoimento Oral, conforme ações éticas sugeridas por Alberti (2005).

2 Entrevista realizada com Adélia Borges, em 4 de julho de 2016, na cidade de São Paulo, com 1 hora de duração.

3 Apesar de Marlene Rodrigues realizar um trabalho de design e trabalhar na área editorial com diagramação de impressos, na época a entrevistada não se considerava "designer", entendendo a si mesma como uma artista visual. Entrevista realizada com Marlene Rodrigues, em 7 de julho de 2016, na cidade de São Paulo via Skype, com 44 minutos de duração. 
O levantamento bibliográfico levou em consideração aspectos políticos e sociais do Brasil nos anos 1980, em especial o cenário do design nacional. Para análise da publicação, além do acervo digitalizado pela Fundação Carlos Chagas (2016a, 2016b), foi utilizada a proposta de Villas-Boas (2009) para nortear o estudo dos principais elementos gráficos e suas relações nas páginas do jornal, a saber elementos técnico-formais - como unidade, harmonia, síntese, balanceamento, movimento, hierarquia, mancha gráfica, estrutura, centramento e eixo - e elementos estético-formais - grafismos, fotografias, ilustrações, tipos ilustrativos, gráficos, tabelas ilustradas, infográficos, etc. É importante levar em consideração que as páginas utilizadas para análise, ao ser digitalizadas por terceiros, perderam uma mancha gráfica precisa, especialmente ao que se refere a espaços brancos ao redor da composição. Alguns documentos originais foram encontrados em fontes como a Biblioteca Florestan Fernandes (Faculdade de Filosofia e Letras da Universidade de São Paulo). Por se tratar de uma publicação antiga e de acesso restrito, contudo, foram utilizadas somente como parâmetro comparativo para análise.

As entrevistas foram conduzidas no mês de julho de 2016, porém com abordagens diferentes. A jornalista Adélia Borges foi entrevistada em seu escritório, na rua Simão Álvares, com uso de roteiro semiestruturado, impressos de apoio e registro com gravador. Já Marlene Rodrigues, em função da distância, realizou sua entrevista pelo software Skype, complementando algumas respostas posteriormente por email para que pudesse analisar melhor as publicações digitalizadas. Os registros da conversa com Rodrigues foram enviados por email para validação da entrevistada.

\subsection{Objeto de estudo: Mulherio}

O Mulherio foi um periódico organizado por um núcleo de pesquisa da Fundação Carlos Chagas (2016b) relacionado ao estudo de gênero, com profissionais de diferentes formações. Tendo seu início em 1981 e término de suas atividades em 1988 (então sob o nome Nexo), o jornal vivenciou duas fases principais: de 1981 a 1983, com seus 15 primeiros números sob responsabilidade de Fúlvia Rosemberg e edição de Adélia Borges, com auxílio financeiro da Fundação Ford; e de 1984 em diante, com mais 24 edições sob direção de Inês Castilho. Da metade ao final de sua existência, contudo, o projeto foi marcado por grandes dificuldades em se manter, recorrendo a venda direta, assinaturas nacionais e subsídios externos.

Para compreender a proposta de Mulherio, foram escolhidas as edições de números 0, 6 e 15, que ilustram respectivamente o início do projeto (sua apresentação ao mundo e consequente proposta), o começo de sua maturidade como veículo de informação (consolidação de seções e conteúdos) e a primeira grande crise de financiamento (findo contrato com a Fundação Ford). 
Para introduzir o leitor aos estudos sobre a imprensa feminista, esse artigo terá como foco as publicações de mídia alternativa dos anos 1980, em especial as publicadas em São Paulo. O objeto de estudo ficará restrito aos anos de 1981 a 1983, por motivos já citados.

\section{CONTEXTUALIZAC̣ÃO}

\subsection{Política, design e anos 1980}

Os anos 1980 são especiais na história do design gráfico. Além do amadurecimento internacional do design como campo após grandes guerras e a criação de diversas escolas, o desenvolvimento de tecnologias de computação proporcionaram novas possibilidades de experimentação, ao mesmo tempo que tornavam, por contraste, processos tradicionais (como litografia ou tipografia) mais baratos. Somadas às mudanças radicais impostas por uma nova Divisão Internacional do Trabalho e a processos intensos de internacionalização dos mercados, os anos 1980 são caracterizados por uma ampla pluralidade de linguagens - desde movimentos marginais e questionadores como punk até a mais abstrata das composições concretistas. O sincretismo de estilos acaba por definir o que Poynor (2010) sintetiza como estética pós-moderna, caracterizada por sobreposições visuais, experimentos tipográficos e fotográficos, bem como questionamentos a pressupostos de escolas clássicas de design (legibilidade, leiturabilidade, grade, composição, etc).

Nesse contexto, países latino-americanos apresentaram singularidades bem interessantes. Ao mesmo tempo que absorveram referências visuais internacionais - especialmente linguagens publicitária e de identidade de marca (branding) dos Estados Unidos -, nações como Brasil desenvolveram soluções próprias a partir de contextos locais, a exemplo do movimento Tropicália, uma adaptação do design pop dos anos 1960/70.

As ditaduras latinas também serviram de motivo fundamental para que grupos sociais direcionassem algumas soluções gráficas dos "países de terceiro mundo", que, por meio da mídia alternativa, apresentavam ideologias e estratégias anti-hegemônicas. No Brasil, essa linguagem se manifesta especialmente em veículos culturais - como capas de discos e cartazes - e em mídia alternativa, especialmente em boletins e informativos de grupos políticos de oposição. Vários jornais como Opinião, Movimento, Jornal da Vila e Lampião serviram como meio para apoiar greves e outras manifestações de movimentos sociais, sendo O Pasquim um dos expoentes mais populares e profissionalizados desse nicho (BORGES, 2016).

Dentre as publicações relacionadas a movimentos sociais, a imprensa feminista ganhou certo destaque no cenário brasileiro. De acordo com Cardoso 
(2004), foram pelo menos 46 publicações só na região Sudeste, cada uma com sua abordagem dentro do movimento feminista. Apesar disso, tais questões enfrentaram grande resistência por parte de outros partidos políticos de oposição, que consideravam as publicações e os encontros feministas subversivos por "desviar o foco" de uma estratégia central (anti-ditadura) para discussões específicas (condição da mulher) (CARDOSO, 2004).

\subsection{Imprensa feminina $x$ imprensa feminista}

Ao passo que o estudo da imprensa feminina abrange a presença da mulher como produtora de conteúdo e como o próprio conteúdo, a imprensa feminista se relaciona nitidamente com movimentos sociais e militâncias entendidas como "de esquerda". É importante ressaltar, contudo, que a imprensa feminina também produzia materiais com questões relacionadas à liberdade e ao papel social da mulher, como indicado por Buitoni (2009). Assim a principal diferença entre ambos os conceitos se dá pela percepção das próprias autoras como parte ou não de uma ideologia formal.

Essas diferenças são importantes para análise gráfica em função do repertório visual utilizado como referência para cada tipo de produção. A imprensa feminista, em especial dos anos 1980, inspirou-se em artistas ou mesmo manifestações marginais para cunhar uma identidade própria, alinhando-se a propósitos considerados mais radicais. Os princípios identificados por Farias (2011), tais como colagem, fragmentação, priorização da tipografia manual, montagens, dentre outros recursos, também são vistos em publicações como ChanacomChana, informativo LGBT contemporâneo ao Mulherio. Em entrevista para a pesquisadora Elizabeth Cardoso (2004, p. 47), Miriam Martinho, responsável pela publicação, confirma:

\footnotetext{
O ChanacomChana tinha uma cara de fanzine, uma coisa anarquista, dentro da proposta punk da década de 80 e dentro da proposta do feminismo radical. As edições variavam entre 11 e 36 páginas de conteúdo, dependia muito de verba, dos temas a serem abordados ou do tempo de publicação entre as edições. Uma equipe muito enxuta, cerca de quatro pessoas, pela publicação. Tinha uma reunião de pauta, improvisada. Nós sentávamos, discutíamos, pedíamos sugestão e voluntários; na medida que os textos iam chegando, a gente ia fechando o jornal. $A$ impressão era em copiadora, o original era feito na base da montagem e colagem com recortes datilografados.
}

Dada a natureza acadêmica do Mulherio, é de se esperar que a lógica visual seja diferente. Para Marlene Rodrigues, a semelhança da publicação com manifestações marginais é "uma feliz coincidência", uma vez em que ela mesma 
enquanto diagramadora não se identificava com movimentos como a cena punk paulista - muito influenciada pela cena londrina (FARIAS, 2011). É possível supor, contudo, que a aproximação do corpo editorial com outras publicações relacionadas a movimentos sociais - Adélia Borges trabalhava no Movimento, enquanto Marlene Rodrigues trabalhava no Jornal da Vila, do movimento sindical do $A B C$ de São Paulo - tenha trazido esses elementos de forma indireta, resultando na proximidade gráfica entre as publicações. Nas figuras 1 e 2 é possível identificar, em ChanacomChana, o uso de tipografias características de processos mais baratos de produção (semelhante a Courier New) e um excesso de estilos, sobreposição de informações na capa e ilustrações.

A imprensa feminista também possui singularidades no recorte estabelecido para essa pesquisa. De acordo com Cardoso (2004), é possível dividi-la em dois momentos principais: a primeira fase (entre 1974 e 1980), caracterizada pela abordagem de temas gerais e sociais, além de seu papel como resistência à ditadura militar; e a segunda fase (entre 1981 e 1999), que dispõe de temas mais específicos à mulher e busca trabalhar com a inserção da mulher no processo de democratização brasileiro. No contexto em que está inserida, Mulherio também foge à regra nesse quesito: por buscar conectar diversos atores na cena feminista, a valorização de uma rede plural de ideias não corresponde à estratégia de nichos de outras publicações feministas, contribuindo para uma linguagem gráfica "menos radical".

Figuras 1 e 2 - Capa e página interna da publicação ChanacomChana, edição no2.

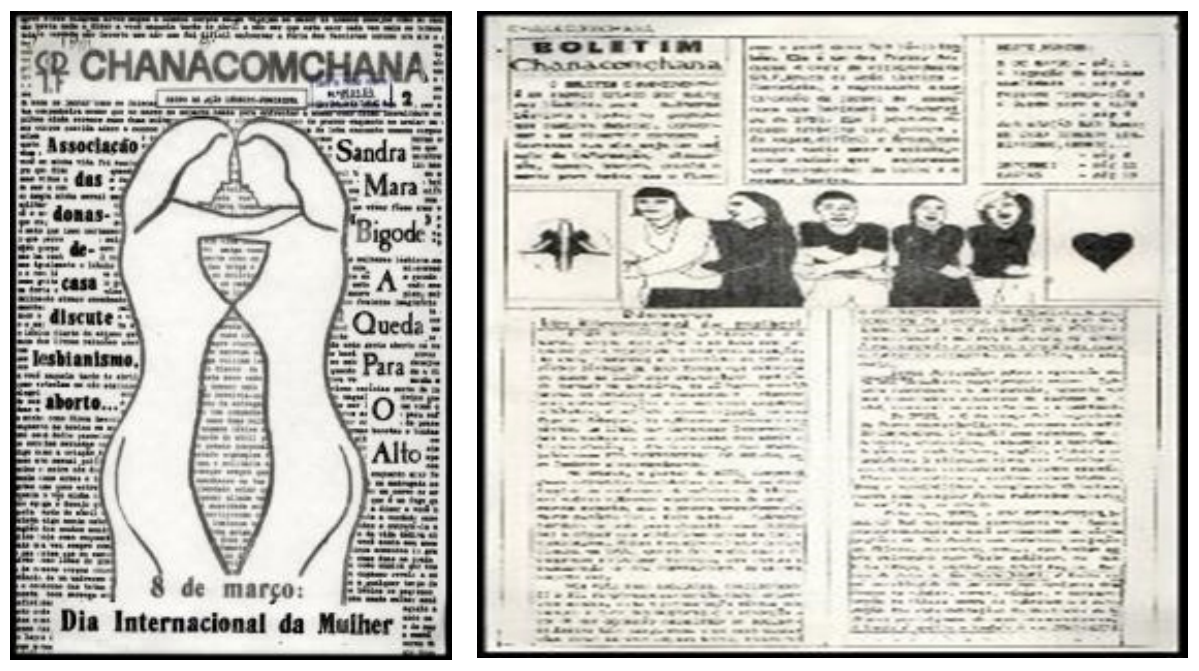

Fonte: Yumpu (2016).

\section{ANÁLISE GRÁFICA}

\subsection{Mulherio e as outras publicações alternativas}

De acordo com Cardoso (2004), a segunda geração da imprensa feminista pós-1974, da qual o Mulherio faz parte, caracterizou-se especialmente pela estratégia de direcionamento de públicos. Mulherio, contudo, seguiu outra 
Rodrigues. Edição não identificável pela figura.

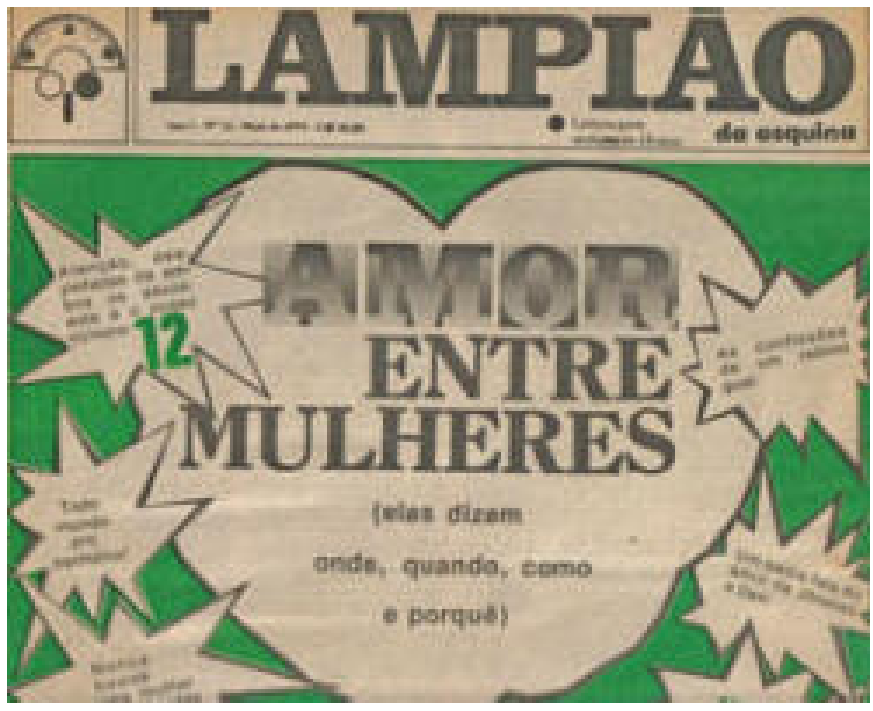

Fonte: Martinho (2012).

direção, com o objetivo de relacionar uma rede já existente de pesquisadoras e apresentá-la a outros atores - como o público em geral e militantes. Como afirma Adélia Borges:

Olha, a gente sempre teve uma postura de colaboração. Cada um tem seu nicho, cada um tem a sua... não propriamente nicho, mas a sua orientação e tudo. E eu era remunerada pelo meu trabalho. Então não era um projeto simplesmente de militância. Claro que, para mim, era uma forma de juntar a minha vida profissional valores em que eu acreditava, coisas que eu acho sérias, que eu... enfim, coisas que eu considero juntar uma coisa com a outra. Mas não era um grupo de militantes.

Mas a gente sempre achou que havia espaço para todo mundo. Não tinha disputa, sabe? Era todo mundo trabalhando por uma coisa. E aí cada uma indo para um lado. Cada jornal indo, atendendo suas definições e tudo. Os outros mais como coletivos, mesmo; aqui mais como uma coisa que tinha um conselho, mas que era tocado mais pela gente, mesmo.

Outro aspecto importante a se levar em consideração ao se analisar o Mulherio em relação a outros boletins independentes é o caráter formal da publicação. Por ser um projeto subsidiado pela Fundação Ford, o corpo editorial era profissionalizado e remunerado pelas edições. Dessa forma é possível compreender a consistência da pauta ao longo de dois anos de publicação, como mesmo número de páginas e seções. Em relação à arte, o projeto disponibilizava de uma verba de baixo custo que permitiu a contratação de editores de artes externos (como Marlene Rodrigues) e ilustradoras/fotógrafas, como é o caso de Nair Benedito. Adélia Borges comenta um pouco sobre esse processo: 
Só para não confundir: não era uma coisa voluntária, feita por pessoas que estavam fazendo isso no fim de semana ou à noite. Eram pessoas que eram remuneradas para isso. Eu era remunerada. Acho que o conselho não era remunerado, também era uma coisa eventual de ir até lá a cada dois meses se tanto. Mas, por exemplo, a gente comprava isso aqui [mostra a foto da Nair]. Não era uma foto dada, era uma foto comprada; o direito autoral dela era pago. Eram valores pequenos, mas eram valores profissionais; uma coisa de pagar, de ter. Então a Marlene não era diagramadora de graça. A gente chamava de diagramadora, mas eu acho que, na verdade, a Marlene era mais que isso: ela era uma editora gráfica, mesmo. Eu acho que, hoje, olhando assim, essas capas que ela fazia têm quase que a força de um pôster. Porque ela passa uma... ela tem uma força de comunicação. Esse diálogo aqui, por exemplo [mostra capa do jornal], mostra a Clarice Lispector, uma mulher super popular.

As seções a seguir descreverão o projeto gráfico de Mulherio por edições, elencando as principais características visuais da publicação.

\subsection{Mulherio\#0}

A primeira edição do Mulherio foi diagramada por Derli Barroso, marido de Carmen Barroso, então integrante do corpo editorial. É interessante observar que os responsáveis pela edição de arte - assim descrito no expediente - já faziam parte da rede de contatos das envolvidas no projeto. Barroso contribuiu apenas na primeira edição.

A primeira edição (número zero), de março/abril de 1981, foi a apresentação do projeto ao público. Possui, assim, um miolo menor em relação às edições posteriores, apresentando em suas quatro primeiras páginas objetivos, pauta e justificativa para o jornal; e, nas três demais, matérias variadas envolvendo a perspectiva da mulher - como um ensaio sobre o Dia Internacional da Mulher, palco de discussões entre movimentos feministas e outros movimentos de esquerda. A análise dessa edição será feita com base nas primeira e quarta páginas, suficientes para ilustrar a identidade da peça.

O projeto proposto por Derli Barroso foi composto pelo logotipo e a estrutura básica do jornal. Para a marca, foi escolhida uma tipografia caracterizada por serifas duplas, quadradas, apoiadas e com baixo contraste de espessura, determinado por um eixo vertical (FARIAS, 2004). As barras e outras estruturas horizontais receberam um acabamento angulado, conferindo um aspecto manual às letras. O prolongamento da parte inferior do logotipo é, talvez, uma das características mais fortes da proposta, assemelhando-se a 
fontes típicas de cartazes psicodélicos dos anos 1980, como visto em trabalhos do designer norte-americano Milton Glaser (2005). O logotipo se manterá, com pequenas alterações, até 1988, época em que a publicação assume o nome Nexo.

A diagramação é próxima de outros jornais da época, com uma grade bem aparente e definida por quatro colunas. A composição, apesar de arbitrária no eixo horizontal - com apoio dos títulos no centro óptico (C.O.) -, é simétrica e bem definida no eixo vertical, dividindo duas colunas para cada lado a partir do centro geométrico (C.G.) da página (figuras 4 e 5). A mancha gráfica é bem delimitada por um quadrado, que envolve o conteúdo. Ao contrário do ChanaconChana, que se apropriava de uma tipografia moderna para texto (sem contraste, serifas quadradas e não-apoiadas), Mulherio é composta por uma fonte clássica/humanista. É difícil estimar com precisão a família utilizada em função das manchas de digitalização; contudo, apresenta-se aqui algumas estimativas para comparação (figura 6). Os títulos são compostos por uma Bodoni, Didot ou similar (alto contraste, serifas em filetes), com o uso de itálicos, mais finos e delicados, próximos ao universo semântico-visual de outras publicações femininas à época.

A unidade da publicação é bem padronizada ao que se refere às manchas textuais, com tipografias que dialogam entre si. A única quebra, contudo, é a introdução do logotipo, que apresenta um estilo visual completamente diferente dos demais tipos escolhidos. O ritmo também é consistente, uma vez que a estrutura da edição (em quatro colunas) não se altera ao longo das páginas.

Figura 4 - reconstrução da grade a partir da primeira página da edição zero.

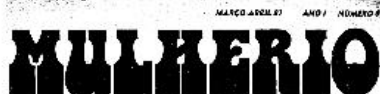

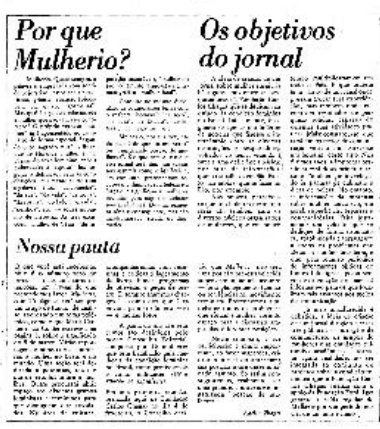

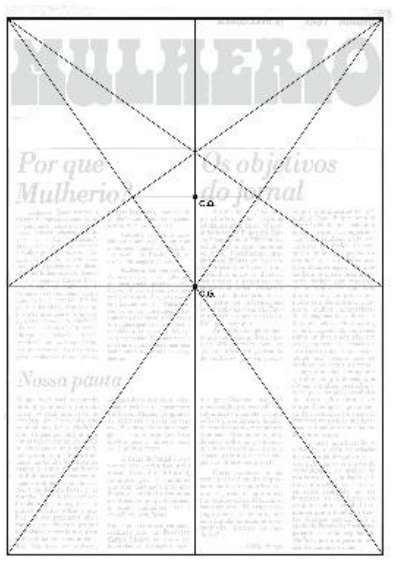

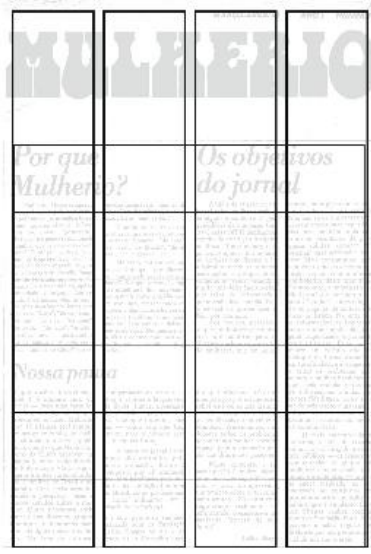

Fonte: Fundação Carlos Chagas (2016b) 
Figura 5 - reconstrução da grade a partir da última página da edição zero.
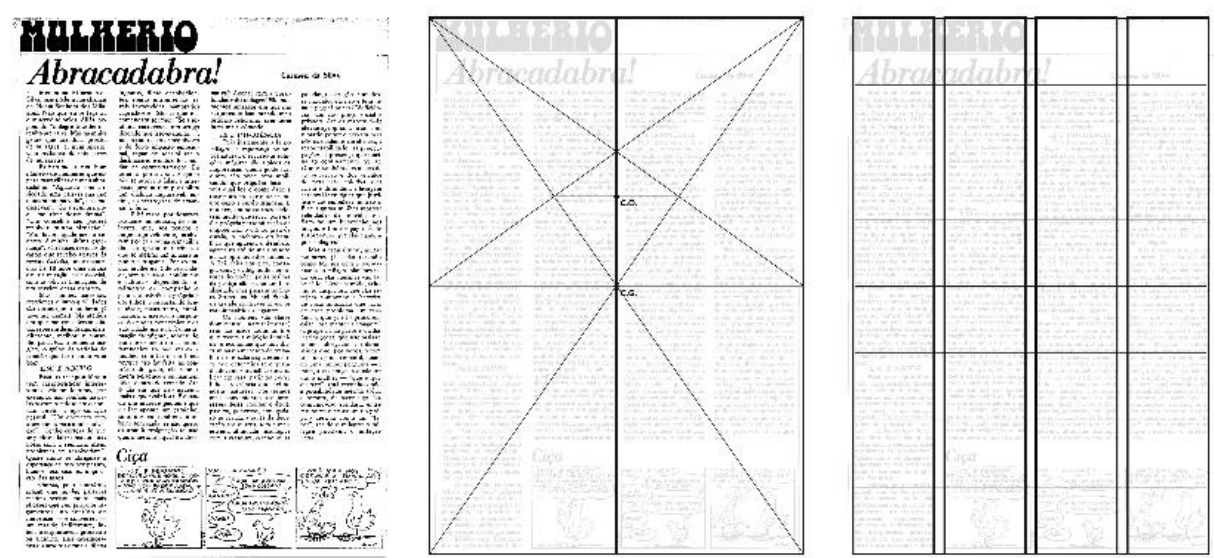

Fonte: Fundação Carlos Chagas (2016b)

Figura 6 - Comparativo tipográfico a partir de recorte de conteúdo da primeira página da edição zero.

\begin{tabular}{|c|c|c|}
\hline Original da publicação & Times New Roman & Garamond \\
\hline $\begin{array}{l}\text { Mulherio. Quase sempre, a } \\
\text { palavra é empregada com senti- } \\
\text { do pejorativo, associada a histe- } \\
\text { rismo, gritaria, chatice, fofoca- } \\
\text { gem ou, então, "gostosura". }\end{array}$ & $\begin{array}{l}\text { Mulherio. Quase sempre, a } \\
\text { palavra é empregada com sentido } \\
\text { pejorativo, associada a histerismo, } \\
\text { gritaria, chatice, fofocagem ou, } \\
\text { então, "gostosura". }\end{array}$ & $\begin{array}{l}\text { Mulherio. Quase sempre, a } \\
\text { palavra é empregada com sentido } \\
\text { pejorativo, associada a histerismo, } \\
\text { gritaria, chatice, fofocagem ou, então, } \\
\text { "gostosura". }\end{array}$ \\
\hline
\end{tabular}

Fonte: Fundação Carlos Chagas (2016b)

\subsection{Mulherio \#6}

A partir da segunda edição (edição \#1), Mulherio já apresenta a consistência de conteúdo que terá até a edição \#14. É também a partir dessa edição que começa a participação de Marlene Rodrigues como editora de arte, decisiva para a identidade desenvolvida para os números posteriores da publicação. Será analisada, contudo, a edição \#6, em que Rodrigues já desenvolvera certa maturidade em relação ao estilo da publicação.

A edição \#6 traz alguns componentes ausentes na proposta de Derli Barroso: a mancha gráfica, apesar de seguir um racional de simetria a partir do eixo vertical (porém com três ao invés de quatro colunas), apresenta variações dependendo da intenção da página. Assim, logo na capa, é possível identificar outro tipo de composição: eixos angulados, a fim de criar linhas de força mais dinâmicas na página. Também é interessante notar que o logotipo, normalmente em destaque em publicações, é parcialmente coberto por outros elementos gráficos (figura 7). A quebra da austeridade do layout proposto por Barroso assim é descrita por Adélia Borges: 
"As primeiras coisas da Marlene foram mais tímidas, de seguir o projeto do Derli, e aos poucos ela começou a fazer uma coisa mais autoral. Mais contundente, também; mais com uma postura de, digamos, de "porrada". De falar "olha, essa é..."

Marlene Rodrigues, ao receber o desafio de diagramar um jornal "tipicamente acadêmico", decidiu subverter uma linguagem tida como tradicional - mancha gráfica bem ampla e grandes quantidades de textos. De acordo com ela, alguns de seus recursos favoritos consistiam em aumentar os espaços em branco nas páginas e associar o texto (com maior espaço entre colunas) a diferentes ilustrações. Também traz ao boletim uma linguagem de revista ao variar o ritmo das páginas, intercalando conteúdos densos de texto com composições que não recaem nos eixos geométricos mais tradicionais. Rodrigues afirma que se inspira em referências que observou enquanto trabalhava próxima do mercado editorial norte-americano.

Além de descontrair o projeto gráfico, a ideia de trazer arte à publicação serviu para ampliar a visibilidade de artistas mulheres e também de divulgar o projeto para um público que não o acadêmico. Alguns elementos gráficos de apoio, como adornos e tipografias manuais também foram utilizados. Os estilos de títulos também foram expandidos, ora utilizando-se de itálico, ora trabalhando somente com negritos.

Como resultado, nas palavras da editora, Mulherio ganhou "uma visualização gráfica mais alegre, mais ousada" (RODRIGUES, 2016). É possível observar esses traços nas figuras 8, 9, 10 e 11, que ilustram o esquema construtivo de algumas páginas do miolo. Na figura 7, o título aparece no meio da página e em diagonal, o que não era muito usual em jornais tradicionais.

Figura 7 - Reconstrução da composição da capa, edição \#6.
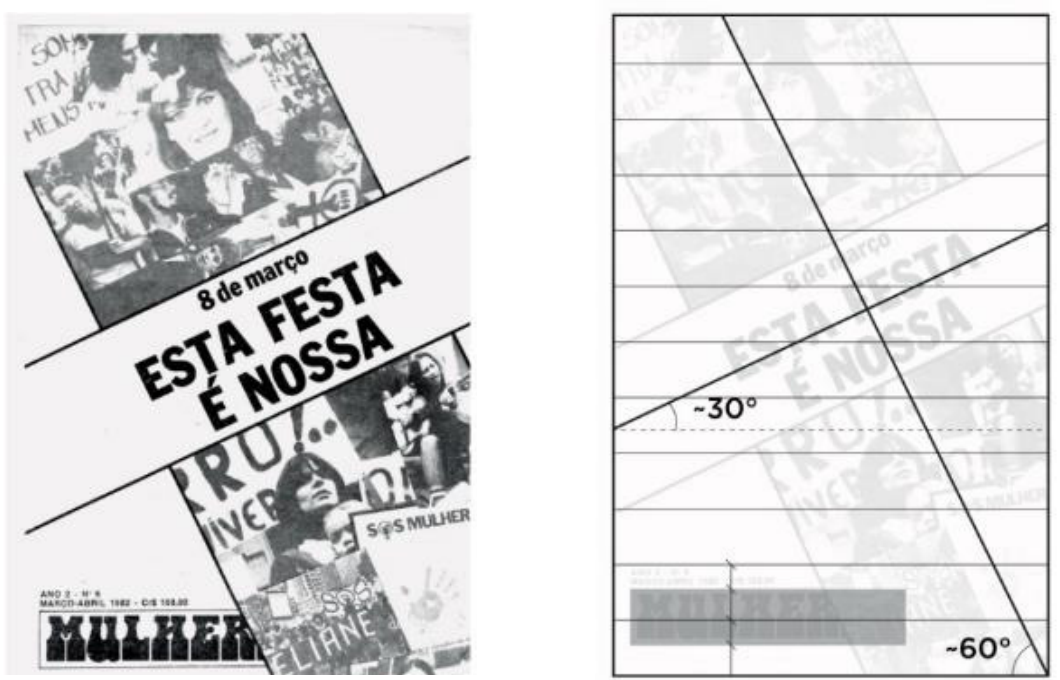

Fonte: Fundação Carlos Chagas (2016a).

Projética, Londrina, v.9, n.2 supl. p. 237-254, nov. 2018 
Figura 8 - Reconstrução da grade da composição de página interna da edição \#6. É possível notar como os espaços em branco aumentaram consideravelmente.

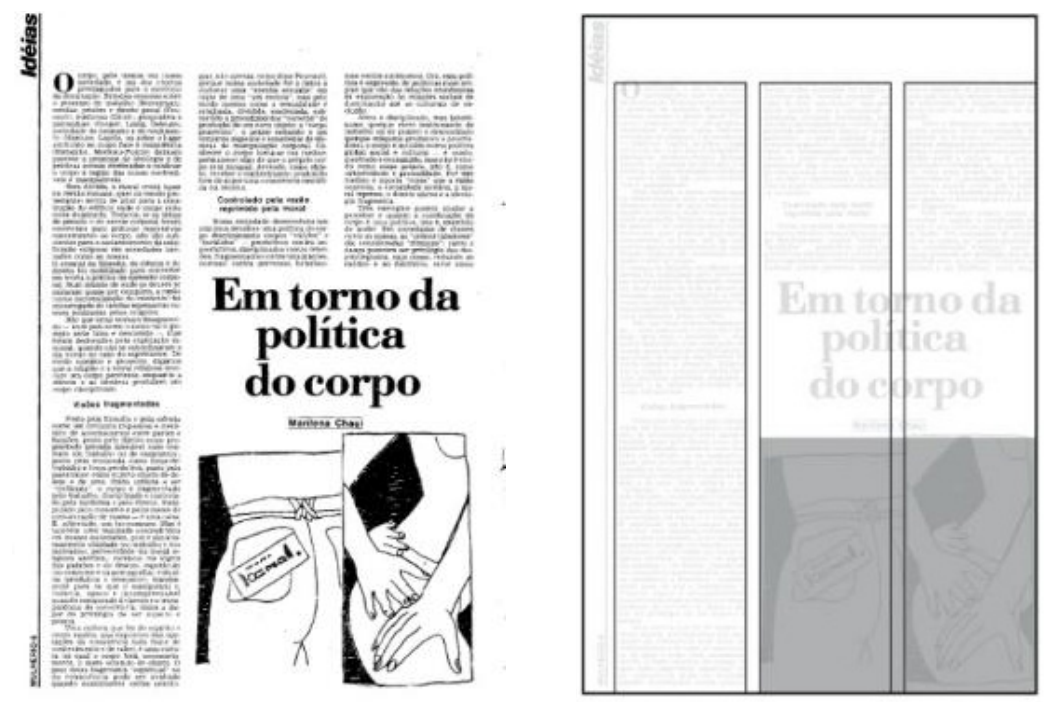

Fonte: Fundação Carlos Chagas (2016b).

Figura 9 - Reconstrução da grade da composição de página interna da edição \#6. A própria coluna se transforma em espaço em branco, equilibrando a citação com a foto no quadrante inferior da composição.
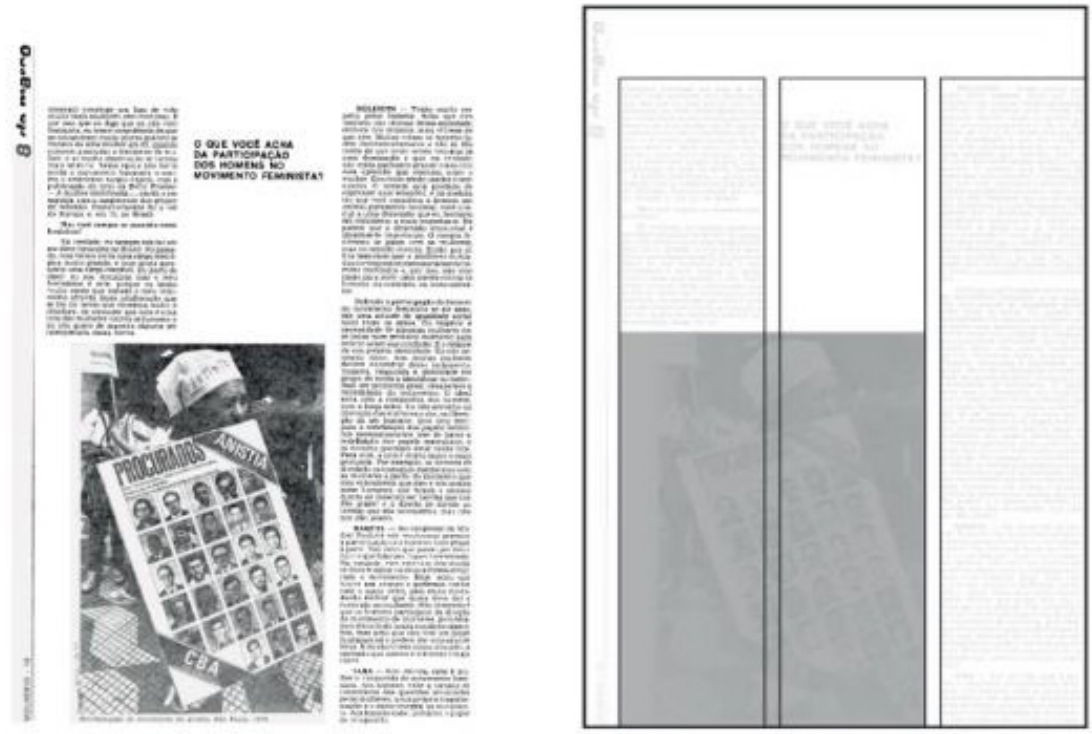

Fonte: Fundação Carlos Chagas (2016b). 
Figura 10 - Reconstrução da grade da composição de página interna da edição \#6. Uso de elementos gráficos de apoiocomo elementos decorativos ao alto e com aspecto de "escrito e desenhado à mão".
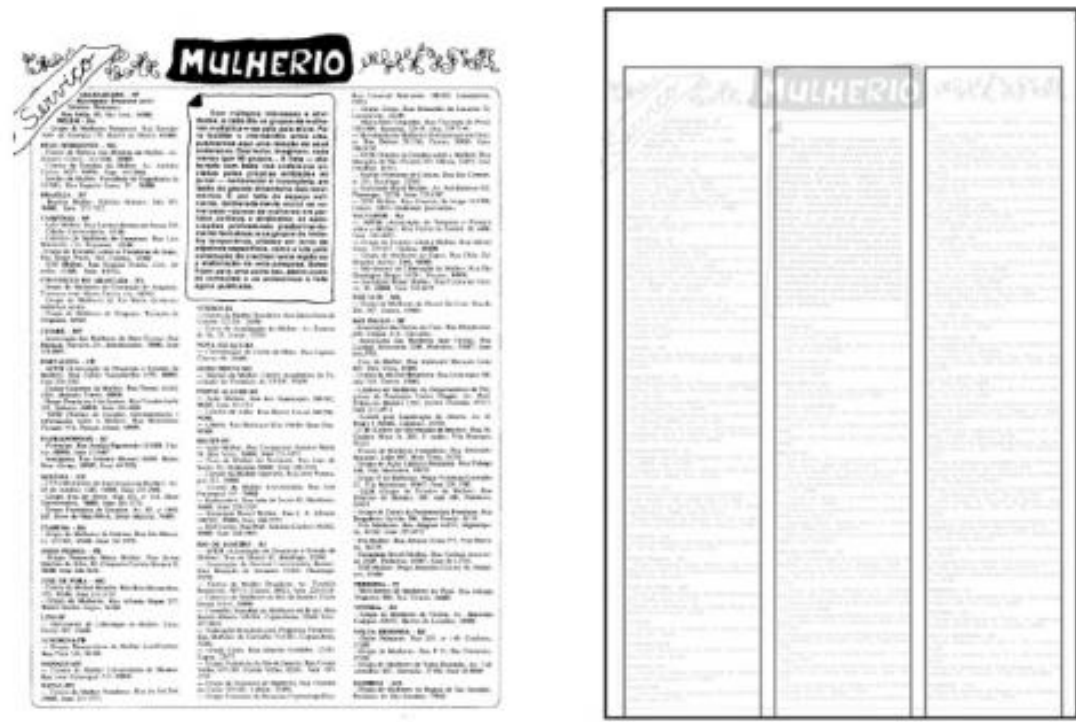

Fonte: Fundação Carlos Chagas (2016b).

Figura 11 - Reconstrução da grade da composição de página interna da edição \#6. Exemplo de página com eixos angulados.
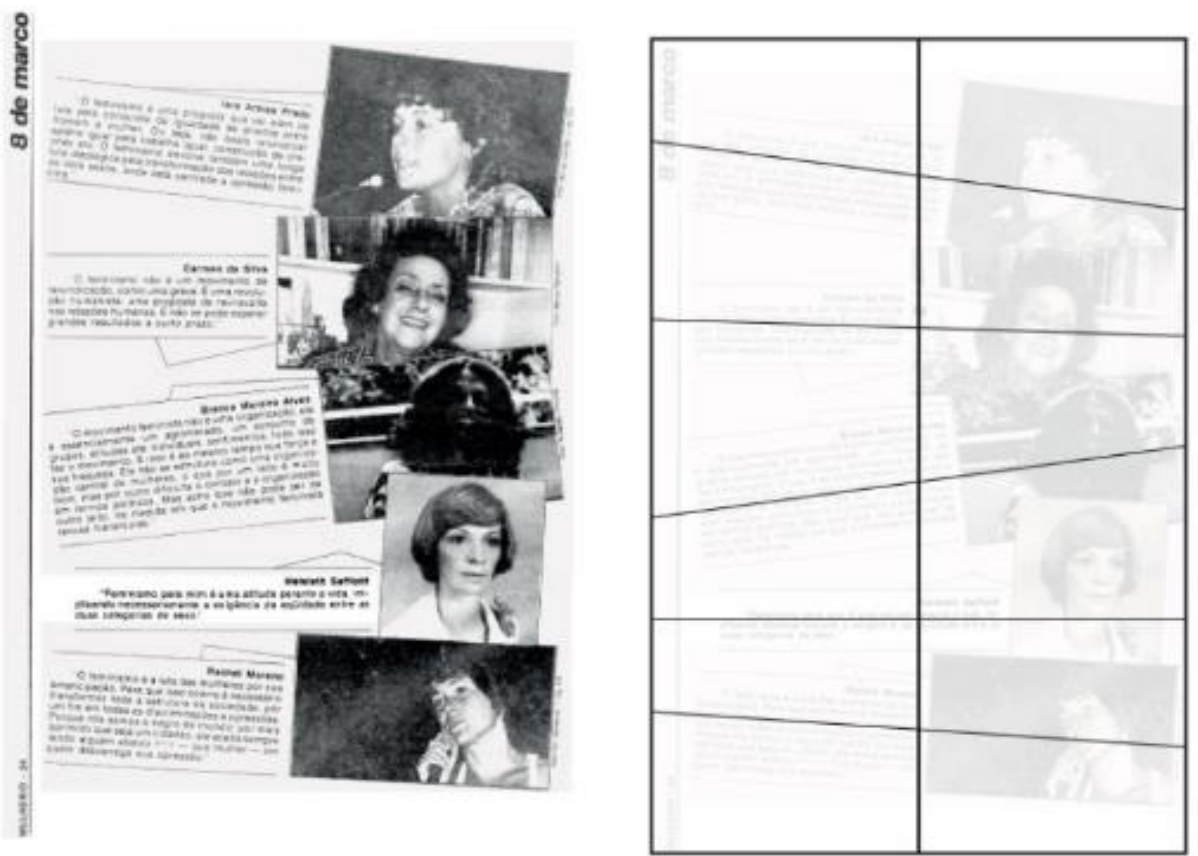

Fonte: Fundação Carlos Chagas (2016a). 


\subsection{Mulherio \#15}

A edição \#16, de setembro/outubro de 1983, foi a última do Mulherio a receber subsídios da Fundação Ford. Por conta disso, a publicação é um convite aos leitores a contribuir com a continuidade do jornal. Nessa época, Marlene Rodrigues deixa a direção de arte do projeto:

Aí, nesse momento, quando ela [Marlene Rodrigues] foi morar na Europa, é que essas outras pessoas passaram a colaborar, como a Micheline, que é uma grande editora de arte e tudo. Você vê que ali Micheline está como edição de arte, não está como diagramadora. Quer dizer, aí já se está descolando da figura do diagramador, que talvez no começo o projeto gráfico era do Derli. (BORGES, 2016)

A mudança de edição de arte é bem visível nas páginas do projeto. Apesar da contundência gráfica permanecer na publicação, Micheline Lagnado e Lilita Figueiredo, então responsáveis pela diagramação do jornal, retomam algumas estruturas propostas por Derli Barroso e acentuam algumas das propostas feitas por Marlene Rodrigues. A variação de ritmo pressupõe, agora, variações de colunas, ao invés de recair nas relações de cheios e vazios, e variações de eixos de composição. Assim, as páginas internas (agora oito, ao contrário das constantes vinte e três dos demais números) ora se organizam em três colunas, ora em quatro. A capa se aproxima mais do estilo de fanzines e outras publicações marginais, como é possível perceber pela composição da chamada manual sobre uma mancha de texto composta em fontes geométricas (figura 12).

O tratamento tipográfico também se altera bastante ao que se refere aos títulos. Apesar da fonte permanecer a mesma para os textos, as chamadas agora são predominantemente não-serifadas, eventualmente com experimentos em relação à forma e a grafismos (figuras 13 e 15).

Figura 12 - Reconstrução da grade capa da edição \#15.
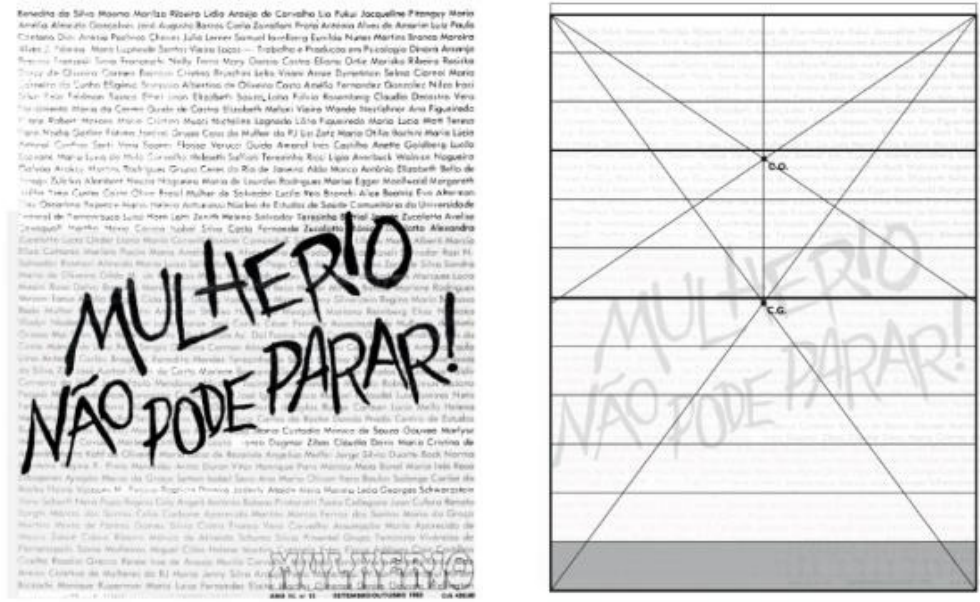

Fonte: Fundação Carlos Chagas (2016a).

Projética, Londrina, v.9, n.2 supl. p. 237-254, nov. 2018 
Figura 13 - Reconstrução da grade de página interna da edição \#15. Os elementos decorativos foram acrescidos para 'quebrar' o ar acadêmico da publicação.
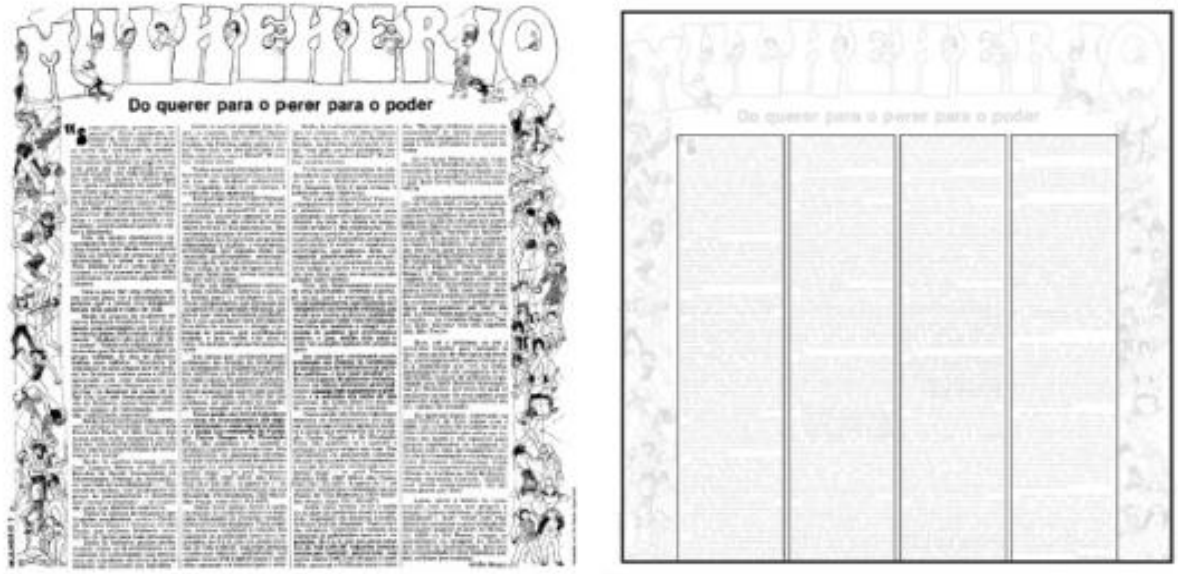

Fonte: Fundação Carlos Chagas (2016b).

Figura 14 - Reconstrução da grade de página interna da edição \#15.
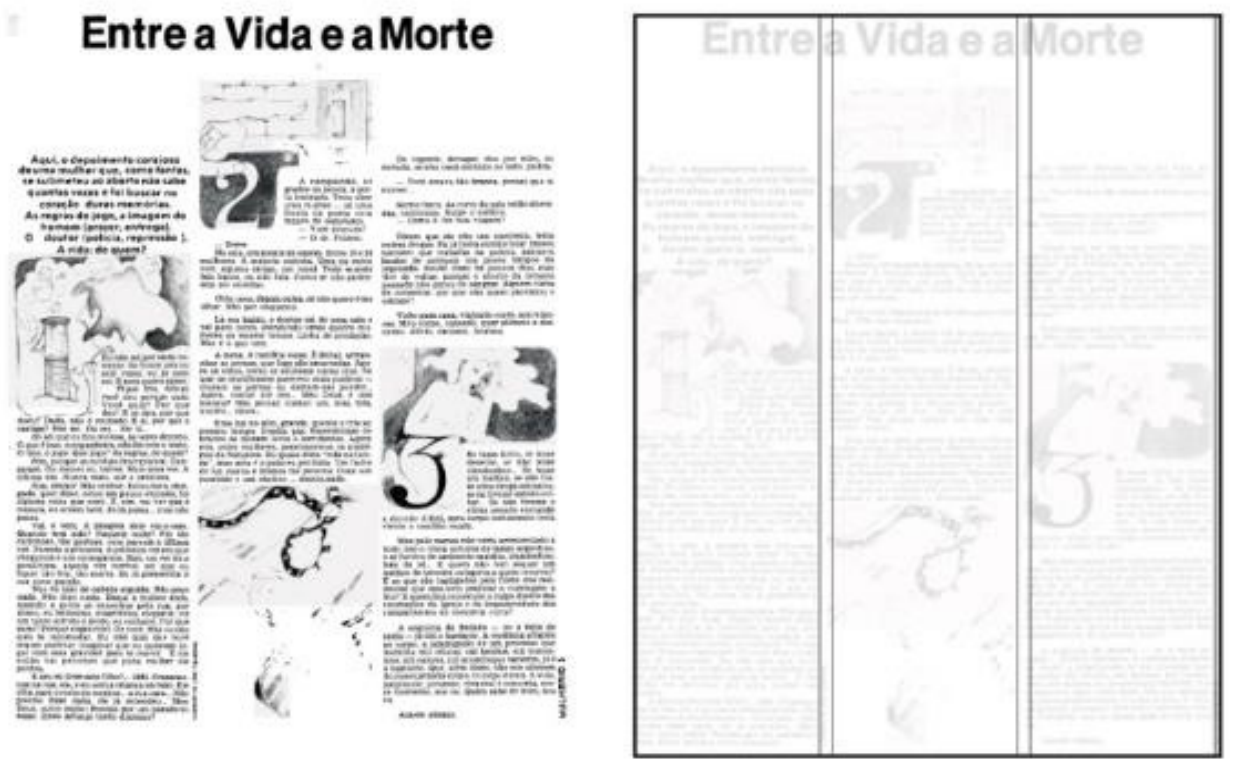

Fonte: Fundação Carlos Chagas (2016b). 
Figura 15 - Reconstrução da grade de página interna da edição \#15.

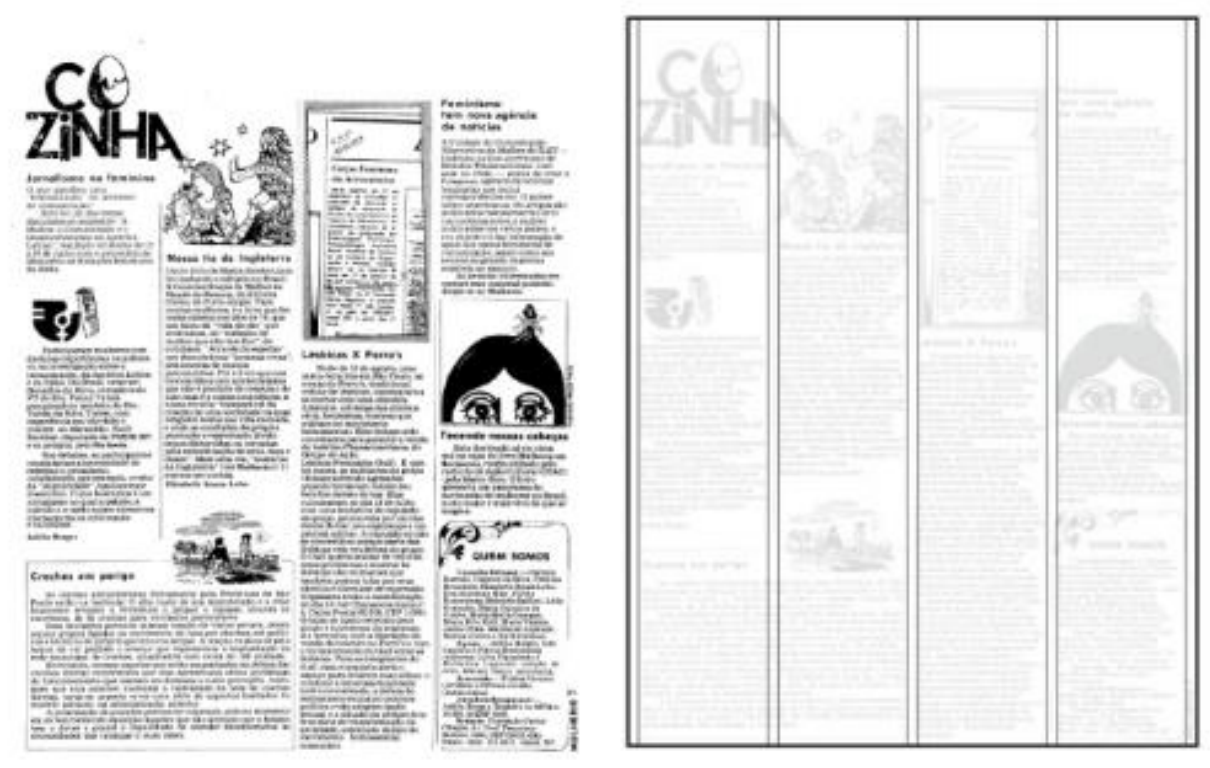

Fonte: Fundação Carlos Chagas (2016b).

\section{CONSIDERAÇÕES FINAIS}

O percurso do jornal Mulherio é muito interessante não só do ponto de vista de um veículo ideológico feminista, mas também por buscar uma conciliação entre o universo acadêmico, as militâncias sociais da época e o público geral. Como resultado, tem-se um jornal que "subverte a linguagem acadêmica ao reduzir a impressão de quantidade de texto com ilustrações e espaços brancos" (Rodrigues, 2016), exercendo experimentos gráficos lúdicos em um nicho até então predominado ora por estruturas mais rígidas (boletins acadêmicos) ou marginais (fanzines e outros boletins de militância). 


\section{REFERÊNCIAS}

ALBERTI, Verena. Manual da história oral. Rio de Janeiro: FGV, 2005.

BUITONI, Dulcília Schroeder. Mulher de Papel: a representação da mulher pela imprensa feminina. São Paulo: Summus, 2009.

CARDOSO, Elizabeth. Imprensa feminista brasileira pós-1974. Estudos Feministas, Florianópolis, v. 12, n. esp., p. 37-35, set./dez. 2004.

FARIAS, Priscila L. Sem futuro: the graphic language of São Paulo city punk. In: DESIGN HISTORY SOCIETY ANNUAL CONFERENCE, 2011, Barcelona. Anais... Barcelona: DHC, 2011. p. 1-16.

FARIAS, Priscila. Notas para uma normatização da nomenclatura tipográfica. In: CONGRESSO BRASILEIRO DE PESQUISA E DESENVOLVIMENTO EM DESIGN, 6., 2004, São Paulo. Anais... Rio de Janeiro: FAAP, 2004. CD-ROM.

FUNDAÇÃO CARLOS CHAGAS. Capas. Disponível em: <http://www.fcc.org. br/conteudosespeciais/mulherio/capas2.html>. Acesso em: 6 jul. 2016a.

FUNDAÇÃO CARLOS CHAGAS. Mulherio. São Paulo. Disponível em: <http:// www.fcc.org.br/conteudosespeciais/mulherio/historia.html>. Acesso em: 6 abr. 2016b.

HOLLIS, Richard. Design gráfico: uma história concisa. São Paulo: M. Fontes, 2005.

MARTINHO, Míriam. Agosto com orgulho: os primórdios da organização lesbiana no Brasil. Disponível em: <http://www.umoutroolhar.com.

$\mathrm{br} / 2012 / 08$ /agosto-com-orgulho-os-primordios-da.html $>$. Acesso em: 6 jul. 2016.

MELO, Chico Homen de; RAMOS, Elaine. Linha do tempo do design gráfico no Brasil. São Paulo: Cosac Naify, 2012.

OLIVEIRA, Luiz Henrique de. Dos Annales à micro-história: alguns apontamentos sobre os avanços da História Social. Revista Virtú, Juiz de Fora, v. 1, 2005. Disponível em <http://www.ufjf.br/virtu/files/2010/03/artigo-1a4. pdf>. Acesso em: jul. 2016. 
POYNOR, Rick. Abaixo as regras: design gráfico e pós-modernismo. Porto Alegre: Bookman, 2010.

SEVCENKO, Nicolau. A corrida para o século XXI: no loop da montanha russa. São Paulo: Companhia das Letras, 2001.

VILLAS-BOAS, André. Sobre análise gráfica, ou algumas estratégias didáticas para a difusão de um design crítico. Arcos Design, Rio de Janeiro, n. 5, p. 2-17, 2009.

YUMPU. Internacional da mulher `^ queda z alto S EOA. Disponível em: $<$ https://www.yumpu.com/pt/document/view/13003522/internacional-damulher-queda-z-alto-s-eoa>. Acesso em: 6 abr. 2016. 